\title{
Time Domain Measures Of Heart Rate Variability In Heavy Workers
}

\author{
Sangita Mithun ${ }^{1}$, Noorzahan Begum ${ }^{2}$, Sultana Ferdousi ${ }^{3}$, Shelina Begum ${ }^{4}$, Taskina Ali ${ }^{5}$
}

\begin{abstract}
Background: Physical inactivity and low resting heart rate variability (HRV) are associated with increased incidence of coronary heart disease. Heavy physical activity is associated with higher heart rate variability and reduces the risk of coronary heart disease Objective: To assess some time domain measures of HRV in order to compare Cardiac Autonomic Function between sedentary and heavy workers. Methods: This cross sectional study was carried out in the Department of Physiology, Bangabandhu Sheikh Mujib Medical University between $1^{\text {st }}$ July 2008 to $30^{\text {th }}$ June 2009 on 30 apparently healthy heavy workers aged 28-50 years from low socioeconomic condition (study group). For comparison 30 age, sex, BMI and socioeconomic status matched apparently healthy sedentary subjects (group A) were also studied. The study subjects were selected among rickshaw-pullers living in the slum areas nearby BSMMU, Dhaka and the controls were from fourth class employee of BSMMU, Dhaka. Heart Rate Variability were assessed by a Polygraph. Several time domain measures of HRV such as mean R-R interval, mean HR, SDNN, RMSSD were analyzed. For statistical analysis, Independent-Samples t-test, and Pearson's correlation coefficient tests were done as applicable. Results: Resting mean heart rate $(\mathrm{P}<0.01)$, SDNN $(\mathrm{P}<0.01)$ and RMSSD $(\mathrm{P}<0.001)$ were significantly lower but mean $\mathrm{R}-\mathrm{R}$ interval $(\mathrm{P}<0.001)$ was significantly higher in heavy workers than those of sedentary control. The mean $\mathrm{R}-\mathrm{R}$ interval $(\mathrm{P}<0.05)$ showed significant positive correlation in heavy workers but significant negative correlation in sedentary workers with BMI. Conclusion: Cardiac autonomic nerve function status may be higher with parasympathetic dominance by increased physical activity.
\end{abstract}

Key words: HRV, Sedentary worker; Heavy worker.

J Bangladesh Soc Physiol. 2011 December; 6(2): 77-83 For Authors Affiliation, see end of text.

http://www.banglajol.info/index.php/JBSP

\section{Introduction}

$\mathbf{P}$ hysical activity is a key determinant of energy expenditure. Several studies confirmed the overall health benefits of physical activity. Regular physical activity reduces the risk of cardiovascular diseases, stroke, type II diabetes, colon cancer, breast cancer etc ${ }^{1-6}$. In addition, globally 1.9 million deaths related to low physical activity has been

Received August 2011; Accepted December 2011 reported by $\mathrm{WHO}^{1}$. Increased adiposity, high lipid profile, and increased insulin resistance may have been considered as link between physical inactivity and coronary heart diseases. Again, disturbances in autonomic nerve function may be associated with low physical activity ${ }^{7}$. Both structured and non-structured physical exercise can act as a preventive therapy for cardiovascular diseases $^{8}$. 
The World Health Organization (WHO) defined physical activity as any bodily movement produced by skeletal muscle that requires energy expenditure ${ }^{1}$. Again, workers are classified as sedentary (Office worker, teacher, lawyer, doctor etc), moderately active (Postman, bus conductor, plumber, light industrial worker etc.) and very active (Coal miner, forestry worker, rickshaw puller etc. $)^{9,10}$.

Heart rate variability (HRV) is a conventionally accepted method to describe variations of both instantaneous heart rate and R-R intervals. Evidences from different studies indicate association between risk of lethal arrhythmias and reduced parasympathetic activities. It reflects the importance of examination of autonomic nerve function ${ }^{11}$.

HRV analysis, a unique tool for quantitative measurement of cardiac autonomic activity has gained worldwide acceptance. Currently analysis of HRV by simple time domain method and statistical time domain method is widely practiced. Common simple time domain measures include mean NN (RR) interval and mean heart rate. Statistical time domain measures include standard deviation of $\mathrm{NN}$ interval (SDNN) and square root of mean squard differences of successive NN intervals (RMSSD). It has been reported that decreased parasympathetic activity may reduce beat to beat variability. Research evidences suggest that sedentary life style may induce a reduction in parasympathetic outflow and it is associated with lower heart rate variability (HRV) with increased incidence of coronary heart diseases ${ }^{9,12,13}$. Conversely, vigorous activity is associated with increased parasympathetic activity and thereby with higher heart rate variability ${ }^{9,14-15}$.

In simple time domain method, variation of mean $\mathrm{R}-\mathrm{R}$ interval and mean heart rate is used to assess the cardiac parasympathetic regulation in healthy adults ${ }^{16}$. Higher mean R-R interval and lower mean heart rate were found in heavy workers than that of sedentary workers ${ }^{17-20}$. Again, lower heart rate was also reported in heavy physical activity than sedentary workers ${ }^{7}$. Some other group of investigators failed to find any effects of regular physical activity on the mean R-R interval and mean heart rate ${ }^{21-23}$

In statistical time domain method, high value of SDNN and RMSSD in heavy workers than sedentary control were found by many researchers ${ }^{7,20,24-29}$. But some investigators found lower value of these parameters in heavy workers than sedentary control ${ }^{30-31}$. Again unchanged values of these measures after physical activity were not uncommon ${ }^{32-33}$.

Mechanical and sedentary life style of our country, especially in urban area is increasing day by day. From the above mentioned information, it is more or less accepted that alteration of HRV parameters were mostly in favour of physically active people, though controversy of this finding were also found. In our country, study of regular physical activity on cardiac autonomic nerve function status by one investigator ${ }^{34}$ creates some awareness of the benefit of physical activity. This information may also help to reduce the cardiovascular morbidity and mortality and to raise consciousness in general population, especially sedentary people of higher socioeconomic status.

In our country, several studies examining the autonomic nerve functions in health and some clinical conditions were also carried out, such as in diabetes, renal failure, aging, obesity and postmenopausal group by conventional method; and on hyperthyroidism by microcomputer based time and frequency domain method. But, no study was undertaken to document the changes of HRV in heavy workers of low socioeconomic condition.

Therefore, this study was carried out to observe the cardiac autonomic nerve function status of heavy workers with low socioeconomic status by analyzing the HRV with domain method. 


\section{Methods}

This cross-sectional study was carried out in the department of physiology of Bangabandhu Sheikh Mujib Medical University between July 2008 to June 2009. Departmental Ethical Committee approved the protocol. 30 apparently healthy male regular heavy workers of low socioeconomic status, aged from 28-50 years were selected as study group (Group B) and 30 age, sex and BMI matched sedentary workers of low socioeconomic status were selected as control group (Group A). Control subjects were selected among the fourth class employee of BSMMU, Dhaka and Group B subjects were rickshaw pullers living in the slum area in Shahabag near to BSMMU. Any subject suffering from systemic diseases, obesity, psychic disorder and drug users specially drug affecting nervous system were excluded from the study. The aim and objectives of the study were explained and they were encouraged for voluntary participation. A written informed consent was taken from each subject. A thorough clinical examination was done and personal history of all subjects were recorded in a prefixed questionnaire. The subject was also asked to avoid tea or coffee at breakfast and to attend at the Autonomic Nerve Function Test Laboratory of the Department of Physiology of BSMMU between 9:00 am to 11:00 am on the day of examination. Then the subject was kept under complete bed rest in supine position for 20 minutes in a cool and calm environment at "Autonomic Nerve Function Test Laboratory". During this test period he was restricted to talk, eat, drink, any physical or mental activity and even sleep. Then a five minutes ECG recording was taken in resting supine position and the time domain measures of the HRV were obtained by a digital polyrite. All data were expressed as mean \pm SD. Statistical analysis was performed by using SPSS for windows version 12.0. Independent Sample t-test compares the mean of time domain measures between groups and Pearson's correlation coefficient tests were performed to correlate mean R-R interval with BMI. P value $<$ 0.05 was accepted as level of significance.

\section{Results}

Subjects of two groups were matched for age and BMI. The mean values of resting pulse rate $(p<0.001), \operatorname{DBP}(p<0.05)$ were significantly lower but mean SBP was lower but not statistically significant in group B than those of group A.(Table I).

Table I : Baseline measures in different groups $(\mathrm{n}=60)$

\begin{tabular}{lccc}
\hline $\begin{array}{l}\text { Parameters } \\
\text { mean } \pm \text { SD }\end{array}$ & $\begin{array}{c}\text { Gr3oup A } \\
(\mathrm{n}=30)\end{array}$ & $\begin{array}{c}\text { Group B } \\
(\mathrm{n}=30)\end{array}$ & P value \\
\hline Age & $\begin{array}{c}35.03 \pm 6.44 \\
(28-50)\end{array}$ & $\begin{array}{c}33.63 \pm 6.75 \\
(28-50)\end{array}$ & $>0.05$ \\
BMI & $21.10 \pm 2.45$ & $19.92 \pm 2.17$ & $>0.05$ \\
& $(15.82-25.34)$ & $(16.14-26.92)$ & \\
Pulse & $71.87 \pm 8.08$ & $64.13 \pm 6.61$ & $<0.001$ \\
(bpm) & $(60-92)$ & $(58-80)$ & \\
SBP & $114.5 \pm 11.7$ & $109.83 \pm 12.28$ & $>0.05$ \\
$(\mathrm{~mm}$ of $\mathrm{Hg})$ & $(90-140)$ & $(90-140)$ & \\
DBP & $73.5 \pm 9.11$ & $68.00 \pm 9.15$ & $<0.001$ \\
$(\mathrm{~mm}$ of Hg) & $(60-90)$ & $(60-90)$ & \\
\hline
\end{tabular}

Figures in parentheses indicate ranges. $\mathrm{SBP}=$ Systolic blood pressure, $\mathrm{DBP}=$ Diastolic blood pressure $\mathrm{BMI}=$ Body Mass Index, Group A= Heavy worker, Group $\mathrm{B}=$ Sedentary worker

The mean values of heart rate $(p<0.01)$,SDNN $(p<0.01)$ and RMSSD $(p<0.001)$ were significantly lower and $R-R$ interval $(\mathrm{p}<0.001)$ was significantly higher in group B than those of group A. (Table II).

Mean R-R interval showed significant $(\mathrm{p}<0.05)$ positive correlation $(\mathrm{r}=+0.406)$ with $\mathrm{BMI}$ in group $\mathrm{B}$ but significant $(\mathrm{p}<0.05)$ negative correlation $(\mathrm{r}=$ 0.437 ) in group A (Figure 1).

Again, mean heart rate showed negative correlation with BMI in group $\mathrm{B}(\mathrm{r}=-0.318)$; but positive correlation in group $A(r=+0.296)$. All these relationships were statistically non significant for both groups. (Figure 2) 
Article

Table II: Time domain measures of HRV in different groups $(\mathrm{n}=60)$

\begin{tabular}{lccc}
\hline $\begin{array}{l}\text { Parameters } \\
\text { mean } \pm \text { SD }\end{array}$ & $\begin{array}{c}\text { Group A } \\
(\mathrm{n}=30)\end{array}$ & $\begin{array}{c}\text { Group B } \\
(\mathrm{n}=30)\end{array}$ & P value \\
\hline $\begin{array}{l}\text { MeanR-R } \\
\text { interval }\end{array}$ & $\begin{array}{c}0.86 \pm 0.11 \\
(0.64-1.07)\end{array}$ & $\begin{array}{c}1.017 \pm 0.10 \\
(0.758-1.175)\end{array}$ & $<0.001$ \\
$\begin{array}{l}\text { Sec) } \\
\text { Mean HR }\end{array}$ & $70.4 \pm 8.74$ & $60.23 \pm 6.91$ & $<0.001$ \\
$(\mathrm{bpm})$ & $(56-93)$ & $(51-75)$ & \\
SDNN & $53.75 \pm 27.07$ & $41.47 \pm 18.07$ & $<0.01$ \\
$(\mathrm{~ms})$ & $(22-122.69)$ & $(22.34-87.88)$ & \\
RMSSD & $82.94 \pm 41.25$ & $66.44 \pm 26.97$ & $<0.001$ \\
$(\mathrm{~ms})$ & $(37.32-191.88)$ & $(32.68-119.29)$ & \\
\hline
\end{tabular}

$\mathrm{R}-\mathrm{R}=$ Interval between successive $\mathrm{QRS}$ complex.Sec $=$ Second $\mathrm{HR}=$ Heart rate, $\mathrm{SDNN}=$ Standard deviation of $\mathrm{NN}$ intervals $\mathrm{ms}=$ millisecond, $\mathrm{RMSSD}=$ Square root of mean squared differences between adjacent $\mathrm{NN}$ intervals

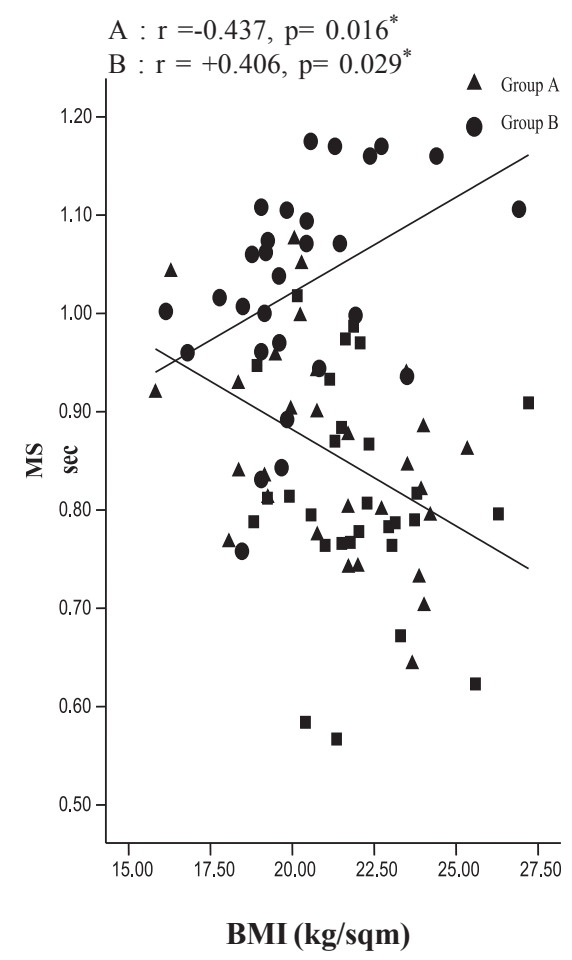

Figure 1: Correlations of Mean R-R interval with BMI in different groups $(n=60)$

Group A: Sedentary workers of low socioeconomic status. Group B : Heavy workers of low socioeconomic status. $*=\mathrm{p}<0.01$
HRV in Heavy Workers

$$
\begin{aligned}
& A: r=+0.296, p=0.112^{n s} \\
& B: r=-0.318, p=0.087^{n s}
\end{aligned}
$$

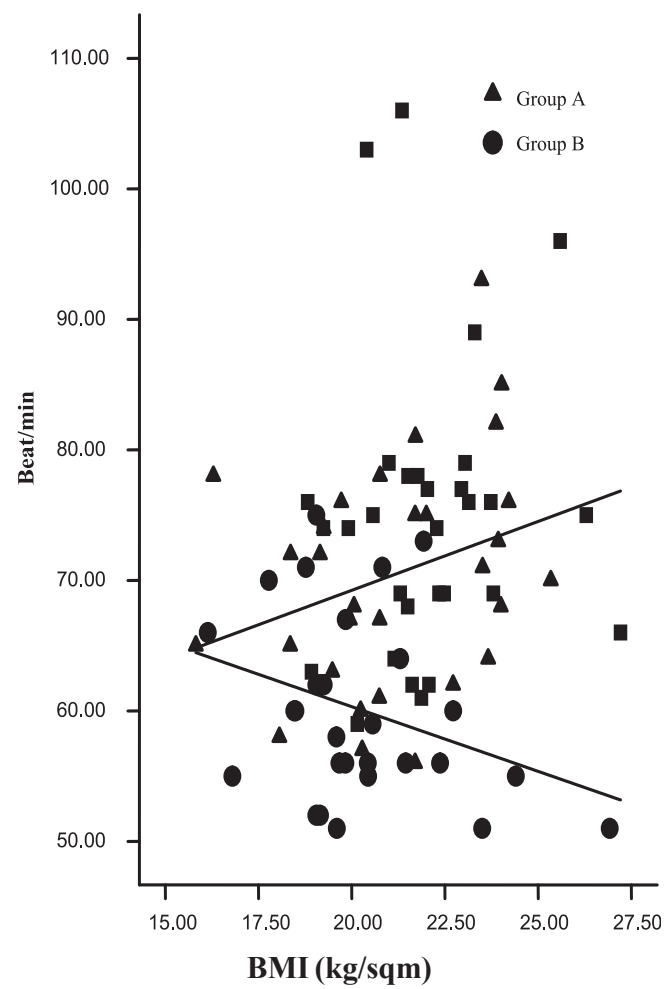

Figure 2: Correlation of mean Heart rate with $\mathrm{BMI}$ in different groups $(\mathrm{n}=60)$

Group A: Sedentary workers, Group B : Heavy workers.

\section{Discussion}

In order to assess the influence of regular physical activity on cardiac autonomic nerve function the present study was undertaken to measure the heart rate variability (HRV) in apparently healthy heavy workers. In this study,some simple and statistical time domain parameters of HRV like mean R-R interval, mean heart rate, SDNN and RMSSD were measured which reflect the cardiac vagal activity ${ }^{11}$. In this study, mean R-R interval, were found significantly higher and the mean heart rate, SDNN and mean RMSSD were found significantly lower in heavy workers compared to sedentary worker. 
Mean R-R interval showed significant positive correlation with BMI in heavy workers but significant negative correlation in sedentary group.

Again, mean heart rate showed negative correlation with BMI in heavy workers but positive in sedentary group though these relationships were nonsignificant.

In the present study, the finding of these time domain measures HRV parameters in healthy sedentary subjects were almost similar to those reported by the various investigators from different countries ${ }^{13,35}$ as well as from our country ${ }^{34}$. In this study, significantly higher mean R-R interval, lower HR, SDNN, RMSSD, are suggestive of higher cardiac vagal modulation in the subjects of the present series which are similar to the findings reported by other investigators. ${ }^{7,24,33,36-37}$.

In the present series, increase in cardiovagal baroreflex sensitivity, the acetylcholine content, choline-acetyl transferase activity in the cardiac tissue and also the cardiac beta-receptors responsiveness may also be responsible for the observed changes in cardiac autonomic activity 37,38 , but it is difficult to comment on these, as all the above mentioned parameters were not possible to measure in the subjects of the present series. Therefore, the exact mechanism involved with increase cardiac parasympathetic activity due to physical activity cannot be revealed from this type of study.

From the above feature it is clear that to maintain cardiovascular health and to prevent cardiac morbidity and mortality, heavy physical activity may play an important role by modifying cardiac autonomic nervous activity towards parasympathetic dominance.

\section{Conclusion}

From this study it can be concluded that cardiac vagal activity may be increased in subjects who undertake regular intensive physical activity. Therefore, intensive physical activity may be more beneficial to maintain cardiac health and in preventing the occurrence of different types of cardio vascular diseases.

\section{Authors affiliation}

1. *Sangita Mithun, Assistant Professor, Department of Physiology, Armed Forces Medical College, Dhaka. Email:sangitamithun@yahoo.com.

2. Noorzahan Begum, Professor, Department of Physiology, Bangabandhu Sheikh Mujib Medical University (BSMMU), Bangladesh. Email:noorzahanbeg@yahoo.com.

3. Sultana Ferdousi, Associate professor, Department of Physiology, Bangabandhu Sheikh Mujib Medical University (BSMMU), Bangladesh. Email: sferdousiratna@gmail.com.

4. Shelina Begum, Professor, Chairman Department of Physiology, Bangabandhu Sheikh Mujib Medical University (BSMMU), Bangladesh.

5. Taskina Ali, Associate Professor Department of Physiology, Bangabandhu Sheikh Mujib Medical University (BSMMU), Bangladesh. Email: taskinadr@gmail.com.

*For Correspondence

\section{References}

1. Global Strategy on Diet, Physical activity, and Health. [Internet]. 2009 [cited 2009 Jan 18]. Available from: http://www.who.int.

2. Manson JE, Frank BH, Janet WHE, et al. A Prospective Study of Walking as Compared with Vigorous Exercise in the Prevention of Coronary Heart Disease in Women. N Engl J Med. 1999;341(9): 650-658.

3. Kaprio J, Kujala UM, Koskenvuo M, Sarna S. Physical activity and other risk factors in male twin- pairs discordant for coronary heart disease. Atherosclerosis. 2000;150(1): 193-200.

4. Sesso HD, Paffenbarger RS, Lee IM. Physical Activity and Coronary Heart Disease in Men. Circulation. 2000; 102:975-980.

5. Stampfer MJ, Hu FB, Manson JE, Rimm EB, Willett WC. Primary Prevention of Coronary Heart Disease in Women through Diet and Lifestyle. N Eng J Med..2000; 343:16-22.

6. Pan American Health Organization. Physical Activity: How much is needed? PAHO. 2002:2pp.

7. Rennie KL, Hemingway H, Kumari M, Brunner E, Malik M, Marmot M. Effects of moderate and vigorous physical activity on heart rate variability 
in a British study of civil servant. Am J Epidemiol. 2003; 158: 135 -143.

8. Warburton DER, Nicol CW, Bredin SSD, Prescribing exercise as a preventive therapy. CMAJ. 2006; 174 (7): doi:10.1503/cmaj.1060147.

9. Classification of workers. [internet].2000. [cited 2008 Nov 27]. Available from: http:// www.kuwaitbusiness.net.

10. Pradhan CK, Thakur S, Mukherjee AK, Roychowdhury A. Energy expenditure of cycle rickshaw pullers in different places in India. Ergonomics. 2008; 51(9): 1407-17.

11. Task Force of the European Society of Cardiology and the North American Society of Spacing and.Electrophysiology. Heart Rate Variability: standards of measurement, physiological interpretation and clinical use. Circulation.1996; 93:1043-1065.

12. Fletcher GF, Balady G, Froelicher VF, Hartley LH, Haskell WL, Pollock ML. Exercise Standards, A Statement for Healthcare Professionals from the American Heart Association. Circulation. 1995;91:580-615.

13. Tulppo MP, Hautala AJ, Makikallio TH et el. Effects of aerobic training on heart rate dynamics in sedentary subjects. J Appl Physiol. 2003; 95: 364-372.

14. Gregoire J, Tuck S, Yamamoto Y, Hughson RL. Heart rate variability at rest and exercise: Influence of age, gender and physical training. Can J Appl Physiol. 1996; 21:455-470.

15. Yataco AR, Lee A. Fleisher LA, Katzel LI. Heart. Rate Variability and Cardiovascular Fitness in Senior Athletes. Am J Cardiol. 1997; 80 (10): 1389-1391.

16. Ewing DJ, Neilson JMM, Travis P. New method for assessing cardiac parasympathetic activity using 24 hours electrocardiograms. Br. Heart J. 1984; 52:396-402.

17. Costa O, Freitas J, Puig J et al. Spectrum analysis of the variability heart rate in athletes. Rev Port Cardiol. 1991; 10(1): 23-8.

18. Janssen MJ, de Bie J, Swenne CA, Oudhof J. Supine and standing sympathovagal balance in athletes and controls. Eur J Appl Physiol Occup Physiol.1993; 67 (2):164 -7.

19. Iellamo F, Legramante JM, Pigozzi F, Spataro A, Norbiato G, Lucini D, Pagani M. Conversion from vagal to sympathetic predominance with strenuous training in high performance world class athletes. Circulation. 2002; 105: 2719-2724.

20. Melo RC, Santos MDB, Silva E, Quitério RJ, Moreno MA, Reis MS, Verzola IA, Oliveira L, Martins LEB, Gallo-Junior L, Catai AM. Braz J Med Biol Res. 2005; 38(9): 1331-1338.

21. Davy KP, Willis WL, Seals DR. influence of exercise training on heart rate variability in post menopausal women with elevated arterial blood pressure. Clin Physiol. 1997; 17(1): 31-40.

22. Leitch JW, Newling RP, Basta M, Inder K, Dear K, Fletcher PJ.Randomized trial of a hospital-based exercise training program after acute myocardial infarction: cardiac autonomic effects. J Am Coll Cardiol. 1997; 29(6): 1263-8.

23. Bonaduce D, Petretta M, Cavallaro V, Apicella C, Ianniciello A, Romano M, Breglio R, Marciano F. Intensive training and cardiac autonomic control in high level athletes. Med Sci Sports Exerc. 1998; 30(5): 691-6.

24. Coats AJ, Adamopoulos S, Radaeli A, McCance A, Meyer TE, Bernardi L, Solda PL, Davey P, Ormerod $\mathrm{O}$, Forfar C. Controlled trial of physical training in chronic heart failure. Exercise performance, hemodynamics, ventilation, and autonomic function. Circulation. 1992;85:2119- 2131.

25. Sacknoff DM, Gleim GW, Stachenfeld N, Coplan NL. Effect of athletic training on heart rate variability. Am Heart J. 1994; 127(5):1275-8.

26. Levy WC, Cerqueiria MD, Harp GD, Johannnessen KA, Abrass IB, Schwartz RS, Stratton JR. Effect of endurance exercise training on heart rate variability at rest in healthy young and older men. Am J Cardiol.1998; 82(10):1236-1241.

27. Iellamo F, Legramante JM, Massaro M, Raimondi G, Galante A. Effects of residential exercise training on baroreflex sensitivity and heart rate variability in patients with coronary heart disease: A randomized controlled study. Circulation. 2000; 102: 2588-92.

28. Martin B, Chantal S, Uranio VA, Stephane D, Francois P, Gabrielle B. Med. Sci. Sports Exerc. 2004; 36 (4):601-605.

29. Buchheit M, Gindre C. Cardiac parasympathetic regulation: respective associations with cardiorespiratory fitness and training load. Am J Physiol Heart Circ Physiol .2006; 291: H451H458. 
30. Migliaro ER, Contreras P,Bech S,Etxagibel A, Castro $\mathrm{M}$, Ricca R,Vicente K. Relative influence of age , resting heart rate and sedentary life style in short term analysis of heart rate variability. Braz J Med Biol Res.2001; 34: 493-500.

31. Buchheit M, Simon C, Piquard F, Ehrhart J, Brandenberger G. Effects of increased training load on vagal-related indexes of heart rate variability: a novel sleep approach. Am J Physiol Heart Circ Physiol. 2004; 287: H2813-H2818.

32. Davy KP, Willis WL, Seals DR. influence of exercise training on heart rate variability in post-menopausal women with elevated arterial blood pressure. Clin Physiol. 1997; 17(1): 31-40

33. Bonaduce D, Petretta M, Cavallaro V et al. Intensive training and cardiac autonomic control in high level athletes. Med Sci Sports Exerc. 1998; 30(5): 691-6.
34. Alom M. Study on Heart Rate Variability in Adolescent Male Athletes. [Thesis] [Dhaka.(Bangladesh)]: BSMMU. 2008.

33. Ishida R, Okada M. Spectral analysis of heart rate variability for the assessment of training effects. Rinsho Byori. 1997; 45 (7): 685-8.

35. Dixon EM, Kamath MV, McCartney N, Fallen L.Neural regulation of heart rate variability in endurance athletes and sedentary controls. Cardiovasc Res. 1992; 26(7): 713 - 9.

36. Wood RH, Wood WA, Welsch M, Avenal PMS. Physical Activity, Mental Stress, and Short-Term Heart Rate Variability in Patients with Ischemic Heart Disease. J Card pulmon Rehab. 1998; 18(4):271-276.

37. Shin K, Minamitani H, Onishi S, Yamazaki H, Lee $\mathrm{M}$. Assessment of training induced adaptation in athletes with spectral analysis of cardiovascular variability signals. Jpn J Physiol. 1995; 45(6):1053 -69 . 